Referencia para citar este artículo: Andrade-Sánchez, F., Lemus-Manrique, L. M., Lizarazo-Mosquera, D. C., \& Merlano-Galvis, E. J. (2018). Tres rupturas decoloniales para repensar la formación profesional en Pedagogía Infantil. Revista Latinoamericana de Ciencias Sociales, Niñez y Juventud, 16(1), 115-127. doi:10.11600/1692715x.16106

\title{
Tres rupturas decoloniales para repensar la formación profesional en Pedagogía Infantil*
}

\author{
FERNANDO ANDRADE-SANCHEZ ** \\ Profesor-investigador Corporación Universitaria Minuto de Dios, Colombia. \\ LINA MARÍA LEMUS-MANRIQUE*** \\ Licenciada Corporación Universitaria Minuto de Dios, Colombia. \\ Deisy Carolina Lizarazo-MosQuera **** \\ Licenciada Corporación Universitaria Minuto de Dios UVD, Colombia. \\ ELBA JANNETH MERLANO-GALVIS ${ }^{* * * * * *}$ \\ Licenciada Corporación Universitaria Minuto de Dios, Colombia.
}

\section{Artículo recibido en octubre 14 de 2016; artículo aceptado en noviembre 11 de 2016 (Eds.)}

- Resumen (descriptivo): Las rupturas acá dispuestas hacen parte de las construcciones epistémicas previas para dar lectura y desarrollo al propósito central de la investigación, orientado a caracterizar discursos y prácticas de docentes y estudiantes del programa de Licenciatura en Pedagogía Infantil de Uniminuto UVD frente a la atención educativa a personas con "dis" Capacidad. Se trata de un estudio cualitativo, abordado desde el paradigma histórico hermenéutico, de tipo descriptivo y alcance interpretativo, que toma muestras representativas de docentes y estudiantes de la licenciatura y los hace partícipes, con quienes se dialoga tomando como punto de partida las construcciones discursivas emergentes tras lecturas y relecturas decoloniales, frente a las formas tradicionales en las que se ha entendido la formación profesional desde la pedagogía infantil en clave de las diversas capacidades humanas en la "dis" Capacidad.

Palabras clave: educación inclusiva, formación profesional, infancia, estudiantes con discapacidad (Tesauro de la Educación Unesco-OIE).

Palabras clave autores: colonialidad de la norma, ruptura decolonial.

\footnotetext{
* Este artículo corto deriva de los resultados parciales (primera fase) de la investigación denominada: Discursos y prácticas de profesores y estudiantes del programa de Licenciatura en Pedagogía Infantil de Uniminuto UVD frente a la atención educativa a personas con "dis"Capacidad. Cofinanciada gracias a la V convocatoria para el desarrollo y fortalecimiento de la investigación en Uniminuto contrato de cofinanciamiento"C115-111". Con fecha de inicio 11 de marzo y finalización en enero de 2017. Área: Sociología; subárea: Temas Especiales.

** Investigador principal. Músico guitarrista, formación profesional en Academia Luís A. Calvo UDFJC y Universidad Central; Licenciado en Educación Especial Corporación Universitaria Iberoamericana; Magíster en Discapacidad e Inclusión Social Universidad Nacional de Colombia (c). Orcid: 0000-0003- 2684-3332. Correo electrónico: ferandrade3@gmail.com.

*** Licenciada en Pedagogía Infantil. Corporación Universitaria Minuto de Dios UVD. Auxiliar de investigación. Orcid: 0000-0001- 5797-2052. Correo electrónico: 1lemusmanri@uniminuto.edu.co

***** Licenciada en Pedagogía Infantil. Corporación Universitaria Minuto de Dios UVD. Auxiliar de investigación. Orcid: 0000-0002- 5163-4543. Correo electrónico: dlizaraz@uniminuto.edu.co

****** Licenciada en Pedagogía Infantil. Corporación Universitaria Minuto de Dios UVD. Auxiliar de investigación. Orcid: 0000-0002- 4282-6308. Correo electrónico: emerlanogal@uniminuto.edu.co
} 


\section{Three decolonial ruptures to rethink professional training in Early Childhood Pedagogy}

- Summary (descriptive): The ruptures presented in this article form part of the epistemological constructions required to develop the main purpose of a research study that aims to characterize the discourse and practices of teachers and students in the Uniminuto UVD Early Childhood Education undergraduate degree in relation to the educational assistance provided to people with "dis"abilities. This is an interpretative descriptive qualitative study that uses a historical hermeneutic paradigm and involves the participation of a representative sample of teachers and students from the undergraduate degree. The researchers engaged in dialogue with these groups, starting with the discursive constructions that emerge from decolonial readings and re-readings based on traditional understandings of the professional formation of early childhood educators in the light of diverse human capacities encapsulated by people with "dis"abilities.

Key words: Inclusive education, professional training, childhood, students with disabilities (Unesco-OIE Educational Thesaurus).

Authors' key words: Coloniality of norms, decolonial rupture.

\section{Três rupturas decoloniais para repensar a formação profissional em Pedagogia Infantil}

- Resumo (descritivo): As rupturas aqui dispostas fazem parte das construções epistêmicas previas que permitem a leitura e desenvolvimento ao propósito central da investigação, orientadas a caracterizar discursos e práticas de professores e estudantes do programa de Licenciatura em pedagogia infantil de Uniminuto UVD frente a atenção educativa a pessoas com discapacidade. Se trata de um estudo qualitativo, abordado desde o paradigma histórico hermenêutico, de tipo descritivo $e$ alcance interpretativo que faz participes a mostras representativas de professores e estudantes da licenciatura; com que se dialoga tomando como ponto de partida as construções discursivas emergentes através de leituras e releituras decoloniais frente as formas tradicionais nas quais se entende a formação profissional desde a pedagogia infantil em pontos das diversas capacidades humanas na "des" Capacidade.

Palavras-chave: educação inclusiva, formação profissional, infância, estudantes com discapacidade (Tesauro da Educação Unesco-OIE).

Palavras-chaves do autor: colonialidade da norma, ruptura decolonial.

-1. El árbol rojo (introducción). -2. Sobre algunas cicatrices. -3. Ruptura \#1: la normalidad del otro y sus discursos. -4. Ruptura \#2: sobre la formación y las miradas. -5. Ruptura \#3: más allá de las miradas de los ojos... migraciones epistémicas.-Lista de referencias.

\section{El árbol rojo (introducción)}

Pensemos en un enorme y tupido bosque de olorosos pinos, que siempre día a día y de manera habitual se extiende frente a la mirada como si se tratase de un interminable infinito verde; ese es el paisaje cotidiano, el escenario predecible; en pocas letras, lo conocido. Si pasara que al terminar una noche, justo en el centro de esa marea verde, un pino en muestra de arbórea valentía cambiara de traje y se vistiera del escarlata más refulgente posible... aún haría parte del paisaje y sin embargo se trataría de un lugar diferente; la ubicación no cambió ni sus vecinos tampoco, pero ya no es el mismo sitio; el lugar cotidiano, el escenario predecible y todo lo conocido, cambió. Así es que si alguien por vez primera observa este paisaje incluirá en su discurso aquel bosque verde con un árbol rojo justo en el centro.

Desde ese ejercicio de pensamiento las letras siguientes alimentan su sentido, en este caso problematizando y mirando más de cerca la formación en la pedagogía infantil, en clave de la atención a las infancias que no están contempladas en los tradicionales libros sobre el desarrollo como sujetos habitantes de la norma. De ahí, pues, que sea un ejercicio de conciencia 
sobre el nuevo paisaje que se erige frente a todas y todos, cuando retos históricamente dejados al margen se posicionan de frente a la realidad social. En este caso hacemos referencia a la atención educativa que se ofrece a estudiantes con "dis"Capacidad u otras formas de ser capaces, esos árboles rojos que reconfiguran los territorios y dan espacio a nuevas formas de visualizar lo que siempre vemos.

Las miradas ecosistémicas sitúan la responsabilidad de asumir a cada quien y sus realidades como una unidad sincrónica; así las cosas, todo ecosistema educativo implica una relación recíproca entre el individuo y su entorno (Choque, 2009); todo lo que cambia en otro modifica a todos. La pregunta central entonces se encarna al pensar que el cambio de paradigma en el trabajo con la "dis"Capacidad, de los escenarios de segregación y rehabilitación en salud únicamente a miradas intersectoriales y ampliadas a las diversas formas de ser capaces, es como un gran árbol rojo en el centro, es decir, a todas luces un nuevo escenario de pensamiento, discursos y prácticas.

¿Podría existir una educación digna, justa y con calidad para todos los sujetos y sus capacidades, si la formación docente no se transforma? ¿Podría entenderse la diversidad de las infancias si los fundamentos desde los cuales se concibe el desarrollo humano, continúan perpetuando ideas estructuralistas que comparan desde sujetos ideales, lo que en cada etapa está por norma lograr? ¿Sería real si en discurso se regulariza al individuo estudiante que cumple la norma y en silencio se asigna la irregularidad a quienes se salen de la teoría del deber ser y hacer? En síntesis, a continuación, miradas, co-visualidades y ejercicios de pensamiento en pro de hacer otras lecturas del paisaje cotidianamente verde, desde los pinos pluralmente enrojecidos.

\section{Sobre algunas cicatrices...}

El hecho de estar juntos - de estar en y con otros - precisa transitar en discursos que sobrepasen la cuestión simple de convivir (Skliar, 2011). Así, y en consonancia con activar y agenciar búsquedas personales y colectivas de formas justas, dignas y con calidad para atender educativamente a la diversidad humana desde la pedagogía, vislumbramos algunas rupturas y aperturas vitales desde los procesos de educación superior en los que se ven inmersas las personas que por proyecto de vida desean dedicarse a la educación de las infancias.

$\mathrm{Si}$ bien el enfoque de la educación inclusiva, y los avances legales, conceptuales y epistemológicos en la comprensión de las capacidades humanas han aportado amplios horizontes, la formación de maestros y maestras respecto de todos los retos que se desprenden del ejercicio de estar con todas y con todos es un asunto para revisar de cerca, pues una escuela de aperturas requiere mentes que permitan en sí mismas la provocación de deconstruir lo entendido y objetivado como normal .

El problema cobra relevancia al tomar distancia de las normas y de lo que se ha encarnado en la experiencia de la escuela tras ellas; ello requiere posturas críticas y propositivas frente a los discursos dominantes que históricamente han establecido la norma y los mecanismos para hacer cumplimiento y defensa de la misma. Las cicatrices acá relatadas demuestran la huella indeleble desde donde se suspende y legitima la imagen del otro biológicamente ideal, como un referente único y enteramente válido de comparación, con base en el poder que se otorga (Foucault, 1972) a quienes son símiles del estándar y desde los cuales se da vida, se cataloga, se relaciona y se valoran para este caso las infancias y sus otredades. El deber ser del cuerpo ha dejado cicatrices en el ver-pensar-decir-actuar de los maestros y maestras que hasta ahora se están haciendo objeto de análisis y deconstrucción.

Provocar ejercicios de pensamiento desde la escuela y sus actores como dinámicas de concienciación y visibilización de dichas cicatrices, lo asumimos para este estudio como un acto conjunto de libertad, ante la otrora colonialidad de los discursos frente al otro y sus diversidades humanas, con evidente punto fundante en el pensamiento médico-biológico

1 Se trata para este ejercicio no solamente de una palabra, sino que aludimos a las normas desde donde se juzga la capacidad, al poder de la nominación normalizada y sus peligrosas sinonimias ocultas en las formas de decir y actuar en la relación con todos y todas. 


\section{FERNANDO ANDRADE-SÁNCHEZ - LINA MARÍA LEMUS-MANRIQUE - Deisy Carolina Lizarazo-Mosquera - ElBa JanNeth Merlano-Galvis}

de génesis eurocéntrica y en las hegemonías de orden neoliberal que se instauraron en la escena mundial, términos peyorativos frente al otro como persona inválida.

Así, y guardando las proporciones y alcances desde los postulados de Quijano (2000), pensar en estas cicatrices es traer al pensamiento las huellas que la colonialidad que el poder ha legitimado históricamente en la escuela, sus actores, discursos y prácticas.

Habría que pensar entonces que la atención educativa en "dis"Capacidad no es solo un asunto afín a psicólogos, terapeutas y educadores especiales. Al ser responsabilidad de todos y todas en el marco de la garantía del derecho, le corresponde a la humanidad en el amplio sentido de la palabra, sin importar la asignatura en la que se especialicen los profesores y profesoras, aun cuando lo normal diga que hay tanto sitios como personas encargadas de ello y lo típico sea acudir a nominaciones estandarizadas para justificar y hacer ver necesarias las distancias en el mismo ejercicio de estar con todos en la escuela.

Una de las cicatrices de difícil borradura es la que hace pensar que en lo concerniente a la atención educativa, es la educación especial la responsable del abordaje a la "dis"Capacidad; esto, a días presentes en el programa profesional en el que adelantamos la investigación, ha resultado en un histórico y misional distanciamiento de la formación en pedagogía infantil, así como también en el quehacer docente de estos licenciados y licenciadas frente a los retos provenientes de estas infancias y sus diversidades.

A este respecto, y en términos de las transformaciones legales y por solo mencionar dos ejemplos representativos, a nivel nacional la ley estatutaria 1618 del año 2013 establece en Colombia las disposiciones para garantizar el pleno ejercicio de los derechos de las personas con discapacidad; y a nivel mundial, desde el año 2007 la Convención Internacional sobre los Derechos de las Personas con Discapacidad trazó caminos de actuación en distintos ámbitos de actuación, entre ellos el educativo. Sin embargo, el cuestionamiento critico se dirige en términos de Dávila, Garmendia y Lauzurica (2016) hacia si estos avances "han sido algo

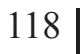

meramente formal y discursivo, o si han tenido repercusión en la práctica ${ }^{2} \ldots$ No obstante, no llega a verse claro el impacto real de toda esta batería de medidas" (p. 155).

Las transformaciones necesarias para hacer frente a estas cicatrices deberán proyectarse directamente en las prácticas y no únicamente quedarse en discursos escritos, pues hacer caso omiso a los desarrollos teóricos y normativos que emergen de la resignificación frente a la "dis"Capacidad y la diversidad en las infancias, a futuro se convertirán en nuevas cicatrices, aun cuando el deber ser de la tinta indique lo contrario.

Esas cicatrices sociales que en el imaginario $\mathrm{y}$ discurso se quedaron, se reprodujeron, aumentaron de tamaño y se hicieron costumbre; se convirtieron en una de las razones que excusa a quienes declaran no estar preparados; eso es trabajo de la Educación Especial; yo trabajo con niños regulares, entre otras expresiones que emergen en el cuestionamiento común del... ¿y ahora qué hacemos?

Por lo mencionado líneas atrás, los retos no son solo frente al uso de las palabras o la omisión de las mismas, sino frente a los discursos que son vividos en las prácticas. Por ello, además de preguntarnos en esta investigación qué se hace para visualizar y re-comprender el paisaje con pinos rojos, buscamos aportar escenarios de ruptura y de resistencia a las tradiciones de formación profesional, apuntando a las crecientes iniciativas por repensar los programas en educación infantil, haciendo visibles cicatrizaciones que de otro modo suelen pasarse desatendidas y continúan presentes, aun cuando cambien los paisajes.

\section{Ruptura \# 1: la normalidad del otro y sus discursos}

Como lo anticipamos, las rutas de objetivación para discursos y prácticas han sido tomadas desde un sentido de oposición y de resistencia a las verdades axiomáticas de la

\footnotetext{
2 Para este caso las prácticas a las que aludimos, hacen referencia a la formación profesional de licenciados y licenciadas en pedagogía infantil y cómo los marcos legales y normativos emergentes impactan directamente la forma como se preparan los pedagogos y pedagogas de esta licenciatura.
} 
normalidad. Advertir los alcances deterministas y estructurales de la normalización en nuestra sociedad permite develar las históricas dinámicas de dominación, ocultamiento y reparación forzada, de toda expresión de la diversidad humana que no se encuentre habitando dentro de los límites del espectro aceptado.

Este ejercicio de criterio invita entonces a hilvanar lecturas y relecturas del otro y de nosotros mismos, poniendo en la palestra lo que proponemos en esta investigación como la colonialidad de la normalidad y sus alcances frente a dominación, anulación y control de los seres y saberes que se distancian y resisten a esta. Este planteamiento epistémicamente resistente se ampara en el concepto de colonialidad expuesto por Restrepo y Rojas (2010, p. 17) como "un patrón de poder que opera a través de la naturalización de jerarquías territoriales, raciales, culturales y epistémicas, posibilitando la re-producción de relaciones de dominación". Es así como esta ruptura busca directamente generar una tensión frente al poder de la norma ante los discursos del otro en la formación de individuos licenciados para las infancias.

La ruptura que proponemos no se limita únicamente a acceder de manera subversiva a lo que se hace y dice en la formación profesional de licenciados y licenciadas; se trata, pues, de provocar ejercicios de pensamiento que consoliden una episteme de resistencia con génesis en dialogar el respeto a la diversidad, a lo plural y sus tensiones ante la igualdad defendida por la norma, desde una gramática decolonial que en términos de Mignolo (2010) se concretiza como un ejercicio de desobediencia epistémica, que "comienza en el momento en el que actores que habitan lenguas y subjetividades racializadas y negadas en su humanidad, toman conciencia de los efectos de la colonialidad del ser y del saber" (Mignolo, 2010, p. 112).

De esta forma, construir discurso desde el otro en exilio tras el velo de lo normal, lleva implícita la construcción conjunta de escenarios de encuentro y re-encuentro en el vivir juntos, la formación de docentes desde perspectivas situadas, críticas y progresistas, de frente a las transformaciones posibles y necesarias encarnadas como ejercicios de pensamiento, que exceden el simple cambio de la terminología a usar para hacer centro en la estructural carga subjetiva que tienen las formas normalizadas de enunciar y entender la relación con el otro.

En consonancia con lo anterior, orientamos este estudio a caracterizar discursos y prácticas de docentes y estudiantes del programa de Licenciatura en Pedagogía Infantil de Uniminuto UVD, frente a la atención educativa a personas con "dis"Capacidad. Así las cosas, una de las primeras tensiones es precisamente la referente a lo que se dice y cómo se comprende lo enunciado sobre otros, especialmente frente a usos de nominaciones y conceptos que parecieran reivindicar la acción docente y que, sin embargo, no dejan de ser colonialismos de la norma sobre lo que se debe hacer, pues así el corpus normativo o las políticas ministeriales lo orientan.

Desde los discursos y las recursivas maneras de nominar al otro en el afán de darle alguna marca, se usan con inquietante regularidad términos como escuela regular o estudiantes regulares, al hacer referencia a personas que al parecer no tendrían "dis"Capacidad, o frente a los cuales el asunto de la diversidad pareciera no hacerles alusión. El regular y su término se convierte desde el discurso en distancia segura; resume estar acogido en la regla, cumplir la norma como lo define etimológicamente desde el latín la palabra regularis o regulare, que a su vez traduce reglar y ajustarse a una norma; el asunto es, ¿a cuál norma?

Lo paradójico en este caso es que el término regular emerge como oposición al uso de la palabra normal y, sin embargo, se trata en sentido y fondo de una mona que, aunque se vistiera de seda, mona se habría de quedar. Al hacer alusión al niño que cumple la regla que lo convierte en regular, encontramos una forma de aludir a quienes presentan alguna condición diferente, pero en esta ocasión ya no en referencia a quienes se salen de la norma para diferenciarlos, sino a quienes habitan dentro de las fronteras de la normalidad, y que cumplen las reglas que los hacen miembros de ese grupo.

La tensión de los regulares es precisamente creerse el cuento narrado por otros sobre ellos; al ser dotados del cumplimiento de la regla y al 


\section{FERNANDO ANDRADE-SÁNCHEZ - LINA MARÍA LEMUS-MANRIQUE - Deisy Carolina Lizarazo-Mosquera - ElBa JanNeth Merlano-Galvis}

comprenderse como regla frente a otros, se habita tras el amparo ventajoso del territorio asegurado por la colonialidad de la norma y desde allí ningún encuentro de comunidad lenguajeante es posible. Ello configura la ruptura expuesta como escenario de pensamiento de aperturas emancipatorias y encarnadoras de encuentros en la pluralidad que nos hace estar con todos en comunidad.

No podríamos negar la antonimia como un componente natural de nuestros lenguajes; de allí que cuando se dice un colegio con niños regulares o un aula de niños regulares, a quienes no cumplen la medición de esa regla se les está bautizando como sujetos irregulares, no apreciados en la medición, por fuera del orden, al margen de la regla. Lo más llamativo es que es una expresión que se usa en muchos casos como buen discurso y, sin embargo, desde la lectura que acá proponemos en clave de colonialidad de la norma, no deja de ser uno de los tantos estigmas, ya no desde el sujeto salido de norma, sino desde la regla y la mayoría.

Esta tensión del discurso se une a una peligrosa fijación en la palabra inclusión, no solo hasta llegar a puntos en donde se dice niños de inclusión, sino hasta llegar a ver esta como el propósito sustancial de la acción docente; entendiendo que la "dis" y la Capacidad humana son todo un campo de estudio (Cuervo, Pérez, \& Trujillo, 2008) en el cual convergen diálogos trasdisciplinares. La educación diseñada para incluir fija linderos en un nuevo tipo de encierro, ahora amparado en el uso social masivo de la palabra.

Lo primero es tener claridades etimológicas ante los vocablos latinos que componen la palabra: in refiere a en o dentro de, y claudere traduce cerrar; así, incluir en términos estrictos es encerrar lo que está por fuera de, lo que irregularmente está donde no debiera. Fijar la mirada en la inclusión como la gran meta es difuminar la meta misma y deslegitimar el estar entre todos y la hospitalidad que ello implica, pues edifica un lugar para quienes están dentro y quienes en las periferias esperan el proceso de redención.

A tener claridad entonces que la postura que asumimos desde esta investigación ante la atención educativa a las infancias y sus diversidades, busca que los maestros y maestras en formación trasciendan el discurso de la inclusión como fin y propósito, y la entiendan como un camino para lograr el derecho a una educación digna de cara a lo que somos como individuos y comunidades, justa a la luz de las diversas formas que tiene de expresarse la capacidad humana y por sobre todo, con calidad, sin apuestas inferiores o empobrecidas en reto y dificultad, bajo el juicio a priori de la incapacidad del otro, que termina siempre por desenmascarar las incapacidades propias.

Indistinto del nombre que se le adjudique a la estrategia, el fin es el derecho y ello no podría significar que los caminos a recorrer sean más importantes que el fin mismo; cabría preguntar ¿qué va a pasar cuando inclusión no sea el término politicamente correcto $^{3}$ y este se transforme?, ¿cambiamos de bandera entonces para ajustarnos a otra denominación? Tal vez una más moderna y más adecuada para lo que en ese momento esté en boga; sin embargo, aun cuando la palabra se modificara, el fin puesto en el derecho, la dignidad, la justicia y la calidad se mantendrían, aun cuando las vías para llegar a este sean re-bautizadas.

Para culminar este punto, y con ello dejar abierta la discusión, la acepción matemática de la inclusión pareciera no ser muy lejana a las interpretaciones que suelen hacerse en el discurso escrito y oral. En la teoría de conjuntos, A se puede considerar incluido en B, si y solo si todos sus elementos son iguales a los del conjunto $\mathrm{B}$; en últimas, la inclusión se vuelve una tarea de igualar y hacer entrar tras la condición de "difuminarse en semejanzas para poder ser incluido" (Andrade-Sánchez, 2016a, p. 2). Es por ello que el asunto de la palabra escrita, la palabra dicha y la palabra vivida producto de las construcciones devenidas de esta investigación, se sustenta en una lectura decolonial que hace necesaria la emergencia de rutas situadas y dignificantes del derecho, $y$ nuestro papel en su garantía.

3 Término complejo que históricamente remonta sus orígenes al ámbito del marxismo-leninismo (Ballester, 2012) para referirse a actuaciones adecuadas según orientaciones del partido; de ahí que posteriormente sea entendido como sinónimo de ortodoxia por la izquierda americana. La frase es bien vista desde alguna perspectiva delineada, aun cuando se caiga en redundancias o con decoro se acuda a eufemismos. 


\section{Ruptura \# 2: sobre la formación y las miradas}

Figura 1. Cuatro miradas.

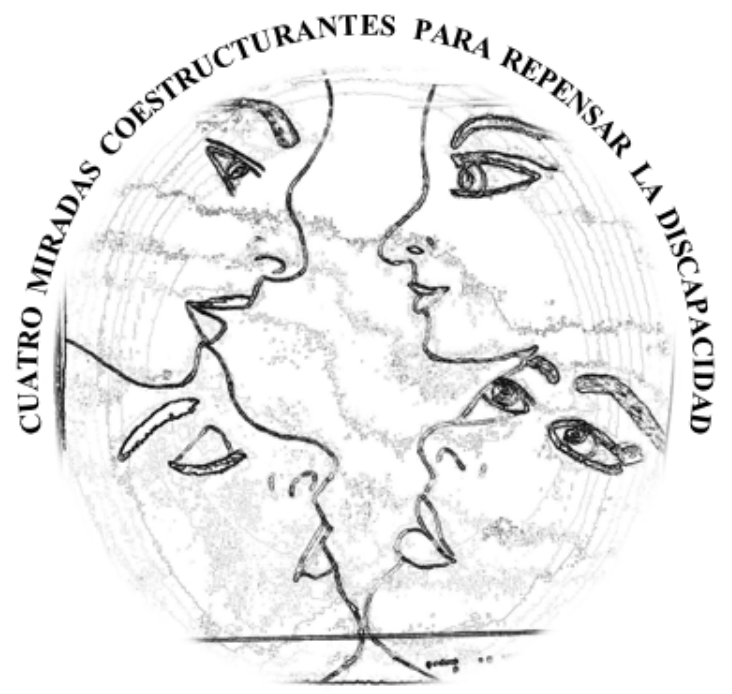

Desde un ejercicio abierto a conocerse y a conocer de sí mismo lo que la boca enuncia para cada quien, realizamos una construcción epistémica situada con el propósito de caracterizar los discursos y prácticas pedagógicas. Ello lo alineamos con el acuerdo grupal por entender el carácter intencional de las emociones como forma de juicio, y la manera en que estas se encarnan no solo como simples percepciones y reacciones frente a objetos y fenómenos, sino que en sí mismas configuran un escenario cognitivo-evaluador (Nussbaum, 2008) que delinea en parte esos paisajes que el pensamiento construye. Para este estudio hemos denominados tales paisajes como territorios simbólicos, entendidos como ese lugar de pensamiento desde donde se lenguajea y se entiende al otro.

Estos territorios a su vez son alineados entre hábitos, creencias y prácticas de socialización del capital cultural desde Bourdieu (1997), así como en lo que Giménez (2001) entiende como una "función principalísima del paisaje en (...) señalar la diferenciación y el contraste entre los territorios en diferentes niveles (...) destacando la supuesta personalidad o tipicidad de los mismos" (2001, p. 6), se consolida el ejercicio de verse como territorio y estudiarse como tal. Principalmente fundados en los ejercicios de co-visualidad planteados por Gómez (2014), que afirma el verse no necesariamente con los ojos sino con el pensamiento proponiendo

(...) verse a uno mismo desde la forma como lo ve el o la co-participante. Y si se quiere ensayar el ponerse en los zapatos de otro/a entonces ha de ser para verse a sí mismo desde allí, no para continuar viendo al otro (p. 281).

Así las cosas, luego del rastreo documental y las disertaciones grupales en torno a cómo lograr una caracterización de discursos y prácticas direccionada a verse a sí mismos, construimos lo que denominamos como 4 miradas co-estructurantes para repensar la "dis"Capacidad, consolidando con ello posibles escenarios simbólicos desde donde se interactúa con el otro desde la supuesta regularidad manifiesta. Cada mirada como territorio simbólico cuenta con una cartografía propia, iconográficamente enriquecida para la lectura y la polisemia, esperando que estas miradas sean a su vez las categorías de análisis de la fase a seguir, en donde se agota la construcción conceptual y se interactúa directamente con los datos; a continuación entonces exponemos cada mirada:

\section{a. Mirada de supresión}

Esta cartografía (Ver figura 2) hace referencia a un pensamiento- territorio supresor; por ello tiene los ojos cerrados y muros en sus oídos, pues no permite alimentar sus paisajes de pensamiento a través de la co-visualidad, recreando un territorio árido, desértico y poco fructífero, una puerta cerrada y fortificada que pretende que nada salga y sobre todo que nada entre.

Esta mirada de supresión ${ }^{4}$ acogería los pensamientos que entiendan al sujeto con "dis"Capacidad como una vida no válida o poco significativa para ser vivida. Se alinearía a la idea de que la discapacidad no aporta a la comunidad; al contrario, podría representar una carga para esta. En el contexto educativo, la mirada supresora se podría evidenciar cuando se discrimina al otro por su capacidad, cuando se omiten acciones, cuando el otro es un problema

$4 \quad$ El término Supresión para la Real Academia Española (2001) significa hacer cesar, hacer desaparecer u omitir, callar, pasar por alto. 


\section{FERNANDO ANDRADE-SÁNCHEZ - LINA MARÍA LEMUS-MANRIQUE - Deisy Carolina Lizarazo-Mosquera - Elba JanNeth MERLano-GaLVIS}

para la clase o la encarnación de más trabajo para el sujeto docente. En este orden de ideas, quien tuviese entonces esta mirada entendería que, aunque por derecho, todos y todas deben ser atendidos con calidad en la educación; suprimirlo, olvidarlo, transparentarlo o violentarlo es una posibilidad latente, otorgada a quienes desde la norma y la distancia solo ven cómo la diversidad sobrevive ante sus acciones.

Este territorio encuentra sus fundamentos en la relación con el otro, en lo que Puig (1990) describe como modelo tradicional, que legitimó en la historia una visión animalista clásica de supremacía y selección de los más fuertes y aptos para la subsistencia. Así mismo, dicho modelo frente a los mecanismos para depuración de la especie se refleja en lo que Palacios (2008) llama un modelo de prescindencia o submodelo eugenésico, desde el cual las prácticas supresoras de la otredad no solo son posibles, sino que son alentadas como adecuadas por los colectivos humanos que se acogen a sus premisas.

En este territorio simbólico habitan las miradas que responden a la pregunta de cómo estar con todos, con soluciones de distanciamiento y segregación; los discursos de aulas e intervenciones apartadas o segregadas en sitios distantes al escenario común de la escuela, viven en la geografía de este territorio que Juárez, Comboni y Garnique (2010) plantean en la práctica como "una segregación de lo anormal, de lo diferente" (p. 60).

Figura 2. Mirada de supresión.

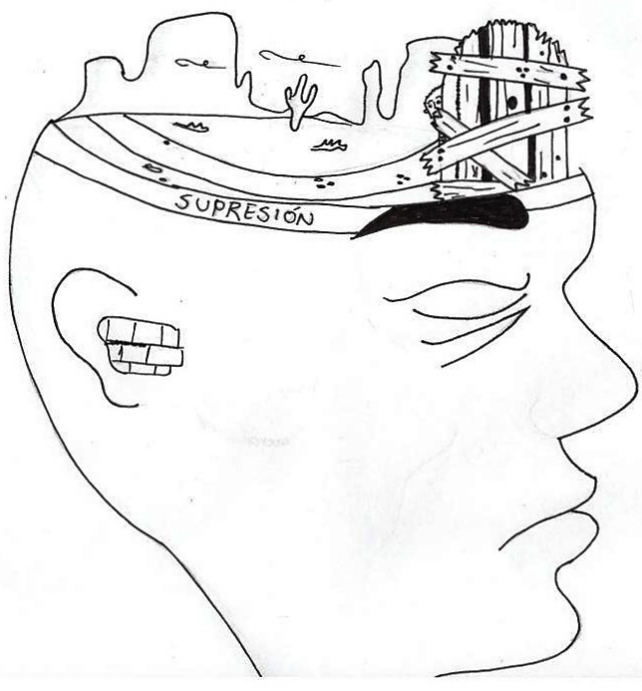

122

\section{b. Mirada compasivo-asistencialista}

El presente territorio de pensamiento permite identificar la concepción de "dis"Capacidad, así como el rol docente frente a esta, centrada en una óptica de lástima y compasión $^{5}$ en la que dominan sentimientos de enajenación como postura principal. En esta cartografía los paisajes están limitados a proporcionar; por ello se evidencia que la cesta del pescado está llena (ver Figura 3). Sin embargo, las cañas no sirven, es una comida que fue puesta allí y que a su vez no fue producto de la pesca, es decir, se suministra sin tomar como posible la capacidad de aprender, intentar o teorizar; en ella, la puerta está entreabierta, con solo una estrecha rendija para atisbar desde la seguridad interna a los otros.

Es la típica mirada asumida cuando se predice que el otro no puede hacer las cosas que los demás sí, y se terminan tomando medidas remediales para compensar la aparente disminución o la falta de capacidades. Esta mirada lleva por génesis y fundamento las históricas prácticas familiares de ocultamiento en hogar, por motivos de endilgar al otro un estado de irremediable asistencia, expuesta por Casado (1991) como una exclusión aniquiladora.

El asistencialismo se sitúa en la mirada como un ejercicio simbólico de aniquilación parcial del otro, que reduce sus capacidades bien sea "por menosprecio o por miedo" (Palacios, 2008, p. 54); sin embargo le desaparece de manera incompleta, no despreciándole ni desapareciendo su subjetividad de la escena de todos, sino relegándole a ser marginado a recibir desde la dependencia y no a crear desde la autonomía. Asimilar la asistencia desde el subestimar la capacidad del otro, implica enmarcar esta mirada en el empoderamiento como dinámica de relación dependiente, en donde el entorno debe prodigar asistencia y buscar suplir las necesidades de ese otro con problemas, como lo menciona Crosso (2010).

5 Si bien la Real Academia Española (2001) define el término como sentir compasión, manifestar o tener inclinación a compadecerse fácilmente, esta conceptualización se articula con la concepción asistencialista y confiere la idea de que la persona con "dis"Capacidad requiere de un auxilio o ayuda permanente. 
Figura 3. Mirada compasivo asistencialista.

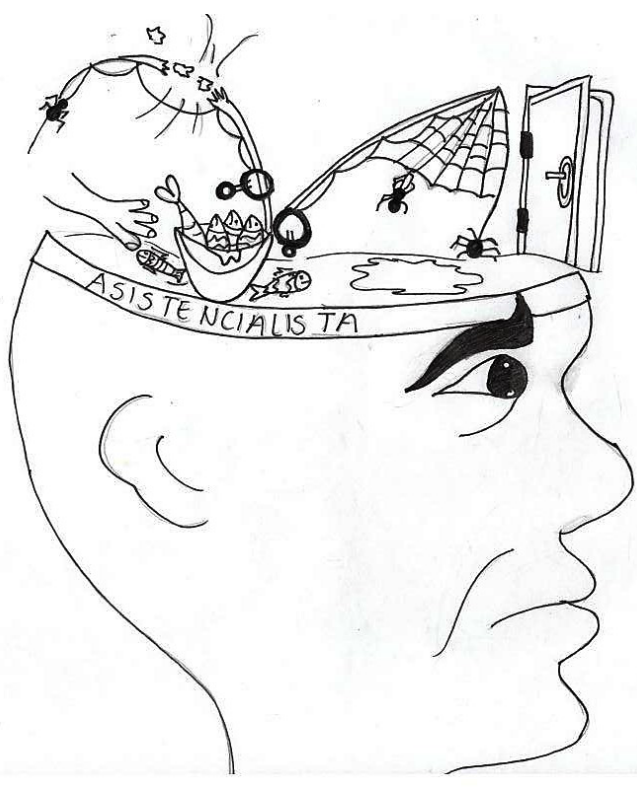

La mirada compasiva asistencialista es evidente cuando desde el discurso se presentan expresiones de lástima o de pesar por el otro que pertenece al grupo irregular; en últimas, se opone a la indiferencia pero se refugia en prácticas y discursos de baja estima, que terminan haciendo por el otro lo que ese otro pudiera lograr; con ello, aunque se persiga lo contrario se legitima en lo escondido la falta de oportunidades, al subestimar la capacidad (Valdés \& Monereo, 2012).

\section{c. Mirada normalizadora}

El territorio de pensamiento acá presente se hace posible cuando el sujeto pondera el deseo de la norma; por ello se evidencia en estos paisajes un panorama clínico articulado con las típicas preocupaciones médicas por el otro y su ser cuando permanece afuera de la norma. Se trata de una mirada que permite sanar, curar, remediar e igualar y normalizar las diferencias, mirando con los ojos sensores, regularizando lo que pueda ser digno de ver (ver figura 4); se tienen oídos que no escuchan a todos, solo a la información que llegue a estos por instrumentos especializados, tecnificados, normalizados ${ }^{6}$.

$6 \quad$ Para la Real Academia Española (2001) el término normalizar hace referencia a regularizar o poner en orden lo que no lo estaba

Rev.latinoam.cienc.soc.niñez juv 16 (1): 115-127, 2018 http://revistalatinoamericanaumanizales.cinde.org.co doi: $10.11600 / 1692715 \times .16106$
Esta mirada se fundamenta en el modelo rehabilitador propuesto por Palacios (2008), en el modelo de rehabilitación de Puig (1990) y en el modelo de accesibilidad de Casado (1991), con génesis en la normalización y la idea de una vida parecida a la de los demás. Esta mirada se alinea a lo planteado por Juárez et al. (2010), y la idea de que "no se trata de segregarlos o de destinarles una institución especial para su educación, sino de incluirlos en las aulas normales" (p. 74). En últimas, valida posibles escenarios de trabajo desde el discurso y la posibilidad de la indiferencia y acercamientos inflexibles frente a quienes no son debidamente regulares (Damm, 2008).

\section{Figura 4. Mirada Normalizadora.}

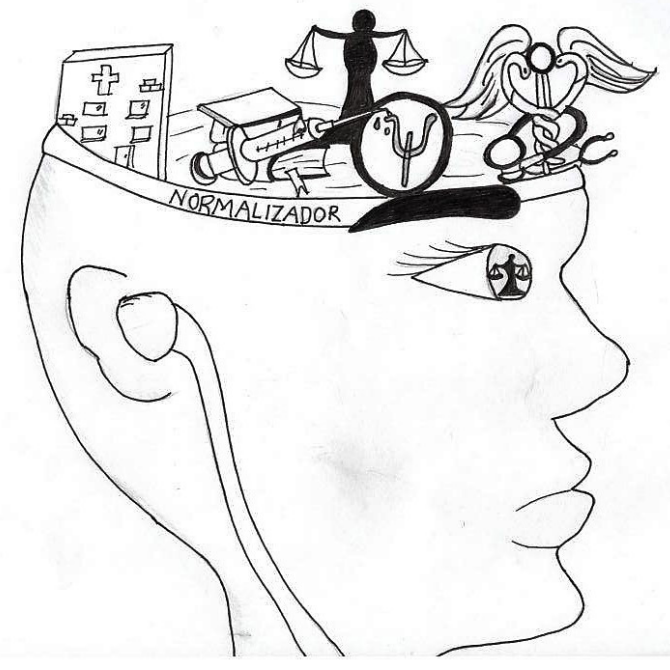

La mirada normalizadora es aquella usada para suponer que con ayuda de especialistas, médicos, terapeutas, psicólogos y educadores especiales, se puede lograr la restauración o normalización. Dichas reparaciones, a ser efectuadas en los cuerpos por fuera de la norma, si bien tienen su sustento en el modelo médico rehabilitador, se materializan en la sociedad por medio de "una ideología de la normalidad acorde a un sistema de producción y reproducción social" (Pava-Ripoll, 2017, p. 6) diseñado para acoger únicamente a los sujetos que se acomoden al estereotipo de norma construido. Es una mirada cuyos paisajes connotan el deseo de un estar con todos homogéneo y parejo, es decir, se suscribe a que todos y todas 


\section{FERNANDO ANDRADE-SÁNCHEZ - LINA MARÍA LEMUS-MANRIQUE - Deisy Carolina Lizarazo-Mosquera - ElBa JanNeth Merlano-Galvis}

somos iguales y vuelve la diferencia un asunto de problema y tensión. No por lo último, los usuarios de esta mirada son férreos defensores de la nominación del niño y niña regular ${ }^{7}$.

\section{d. Mirada emancipadora}

En esta cartografía evidenciamos diferentes migraciones epistémicas a través de la brújula de la co-visualidad. Prima aquí la visualidad de un yo desde la visualidad de otro (Gómez, 2014), desde donde es posible retroalimentarse de forma bidireccional, mirando con el pensamiento; por ello se advierte en la metáfora los ojos bien abiertos, los oídos atentos y una sonrisa que permite identificar las rupturas de las cadenas que sesgan el nuevo paisaje; estas marcan el cruce eficaz de la cartografía que delimita los territorios transitados una y otra vez. Por otro lado, representa la libertad emancipadora figurada en el ave (ver figura 5) descubridora de nuevos terrenos desde la relación con el otro ${ }^{8}$. Finalmente, se encuentra una puerta abierta que simboliza la entrada de nuevas realidades; sin embargo, a su vez es una puerta de entrada y de salida.

\section{Figura 5. Mirada emancipadora.}

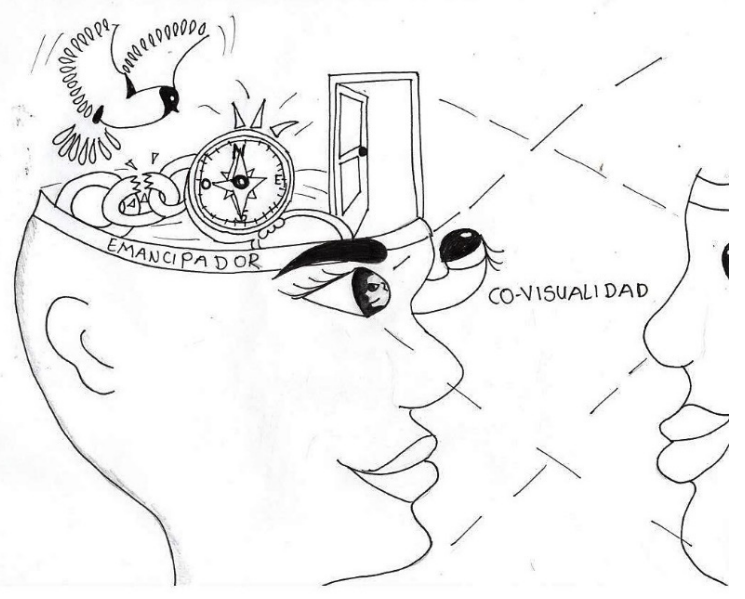

$7 \quad$ Entendiendo como lo único que nos hace ser iguales entre todos, el marco de comprensión y actuación del derecho y la condición humana; y que es desde nuestras diferencias y nuestra inherente diversidad, que buscamos y propendemos por rutas diferentes y variadas para acceder a ese derecho común.

8 Es posible definir el término emancipación como la liberación de algún yugo, como lo plantea la Real Academia Española (2001), que le confiere un significado de liberarse de cualquier clase de subordinación o dependencia.
La mirada emancipadora sería identificable en discursos que se orienten al ejercicio conjunto de la revisión desde sí mismos; esta asume el acto de visualizar como algo más que solo ver, en la medida en que significa un acto compartido de liberación; una mirada que redunda en dinámicas de co-creación de una nueva lógica para entender la relación con el otro y las opresiones históricas y actuales en las que se interactúa constantemente.

El escenario de pensamiento que emerge como acto colectivo de liberación, posiciona el ser y el hacer docente en la capacidad para diferenciar e identificar teorías, conceptos, actores, metodologías, discursos y prácticas que sean opresoras del pensamiento emancipador, y que puedan ser invisibles ante la visualización, al hacer parte del sólido corpus de prácticas naturalizadas en la tradición de la formación de maestros y maestras. Esta mirada entonces, como escenario de pensamiento, es en sí misma resistencia a la tradición dominante, y a su vez una oportunidad para tomar postura situada ante las opresiones que hubiese presentes en esta formación profesional; así, desde las líneas de Freire (1995):

Los opresores de ayer no se reconocen en proceso de liberación. Por el contrario, se sentirán como si realmente estuviesen siendo oprimidos. Es que para ellos, formados en la experiencia de los opresores, todo lo que no sea su derecho antiguo de oprimir, significa opresión ( $\mathrm{p}$. 38).

Esta mirada está sustentada desde el modelo social recopilado por Palacios (2008), desde el modelo de Autonomía personal propuesto por Puig (1990), así como, de la mano con Hahn (1988, p. 149), desde la idea de que la "dis"Capacidad "surge del fracaso de un entorno social estructurado a la hora de ajustarse a las necesidades y las aspiraciones de los ciudadanos"; aunado a los desarrollos de los modelos social y de autonomía, se encuentra consonancia con las ideas de Walker (2013), quien aporta a esta mirada desde la idea de poner en el centro el derecho humano, y comprenderlo como "derecho capacitador" ( $\mathrm{p}$. 4). Por último, se trata de un hacer en práctica desde discursos centrados en la capacidad que 
logren mejores actitudes frente al cambio, desde el conocimiento y la capacitación suficiente de los maestros y maestras (Avramidis \& Norwich, 2002).

Así entonces culmina la presentación de las miradas construidas y con las que esperamos hacer un ejercicio de lectura co-visual de los discursos y prácticas que se encuentren tras la recolección de información; corresponden a su vez a la plataforma epistémica construida de manera situada para desde adentro proyectar la mirada y con ello encontrar las rutas que permitan el tránsito desde las experiencias opresoras en la relación con otros y en la diversidad de ser y hacer.

\section{Ruptura \#3: más allá de las miradas de los ojos... migraciones epistémicas}

Las ampliaciones y exploraciones discursivas que se desencadenarán tras la caracterización de discursos y prácticas en la investigación, las hemos proyectado para que no se conviertan en un mero ejercicio de reconstrucción histórica, sino que, al contrario de ello, presenten un escenario de tensión y conflicto hacia sí mismos y sus formas de pensar al otro. Lograr co-visualizarse como ejercicio de transformación individual y conjunta es consonante - según se comprende desde Honneth (1997) - en términos de un hecho social como la lucha entre el reconocimiento que permita hacer emergencia de una nueva lógica moral desencadenante de re-significaciones hacia lo que normalmente se comprende por la norma y en relación con quiénes son los sujetos encasillados en la misma.

Subyace entre las líneas una provocación a generar movilidades de pensamiento $\mathrm{y}$ visualidad, rutas y posibilidades para migrar desde los territorios que, fundados en una nueva lógica, puedan ser comprendidos cartográficamente como asunto de necesaria movilidad, de inevitable vuelo en helicóptero entre sí mismos (ver figura 6). Así entonces, la provocación evoca a migrar o trasladar el pensamiento hacia otros paradigmas que superen la dualidad del capaz-incapaz y se sitúen en escenarios de relación democrática y pluralmente abiertos, en los que "tengan cabida, de manera equitativa, intereses, necesidades y orientaciones diversas" (Cifuentes, 2008 p. 135).

¿Quién ve?... ¿cómo se entiende el acto de mirar sino como un ir a otros paisajes desde las propias cartografías? En el espacio imposible de los ojos y sus limitaciones ópticas, solo se perciben apariencias, máscaras y sombras que podrían lucir como correctas, aunque tras ellas resida la dis-capacitante mirada que compara desde la norma la cercanía con la biología ideal del cuerpo. Cuando el acto de conocer no está atado al producto de los ojos y sus miradas paridas entre luces, es posible conocer con profundidades más humanas; así mismo acontece cuando las visualidades no necesariamente ópticas se encarnan con otros: se mira con el pensamiento cuando el otro es igual en la horizontalidad de las capacidades humanas.

Figura 6. Migraciones epistémicas.

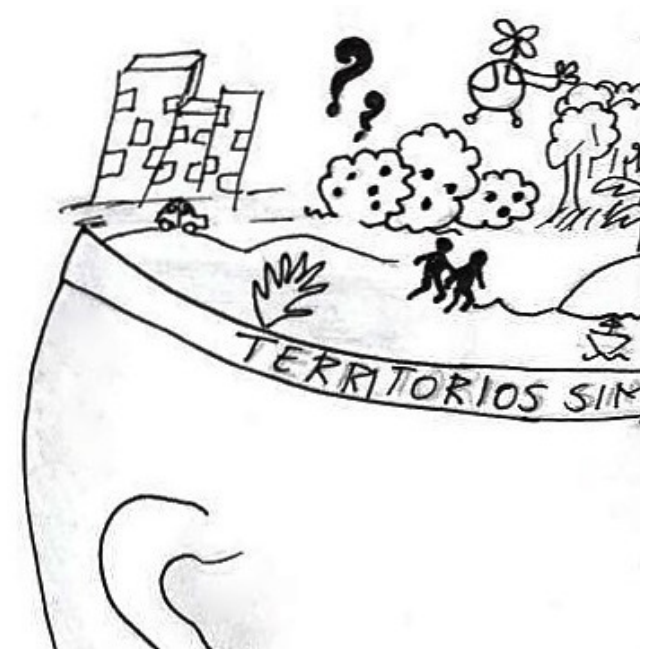

La verticalidad en la escuela y la sociedad solo permite ver al otro por fuera de sí mismo, como algo extraño que evoca una realidad irreconciliable con la idea que se tiene del deber ser; en otras palabras: para conocerse es vital verse, sentirse y pensarse con otros. Toda mirada o apreciación que solo tenga un único ejercicio de pensamiento será incompleta hasta que otros se sumen y desde la alteridad enriquezcan su visualidad... su humanidad.

Las cuatro miradas propuestas son un instrumento similar a un caleidoscopio, 


\section{FERNANDO ANDRADE-SÁNCHEZ - LINA MARÍA LEMUS-MANRIQUE - Deisy Carolina Lizarazo-Mosquera - ElBa JanNeth Merlano-GaLVIS}

mixtura y uniones varias en el ejercicio de co-estructurarnos desde el entendimiento y conocimiento del otro en sí mismos y la disparidad de seres y saberes en la capacidad humana. En pocas palabras, se requiere dejar de ver hacia afuera para co-visualizar desde los espacios en donde todos podemos estar. La tercera ruptura, por ende, es una invitación a afrontar las transformaciones que sean necesarias en los discursos y las prácticas, pues si solo cambian las palabras, pero las bocas, las manos y miradas siguen siendo fundadas en saberes ajenos a la diversidad (AndradeSánchez, 2016b), en últimas se terminará regularizando al esquivamente citado como sujeto irregular.

\section{Lista de referencias}

Andrade-Sánchez, F. (2016a). Inclusión, una apuesta por retornar a lo simple. Boletín el Minuto Pedagógico, (2), 16.

Andrade-Sánchez, F. (2016b). Manos, miradas $y$ silencios otros... resignificaciones culturales hacia una música propiamente Sorda. (Tesis de Maestría). Universidad Nacional de Colombia, Bogotá, D. C., Colombia.

Avramidis, E. \& Norwich, B. (2002). Teacher's attitudes toward integration/inclusion. European Journal of Special Needs Education, (17), 129-147.

Ballester, M. (2012). Lo políticamente correcto o el acoso a la libertad. Cuadernos de Pensamiento Político, (34), 171-201. Recuperado de: http://www.jstor.org/ stable/41444846.

Bourdieu, P. (1997). Capital cultural, escuela y espacio social. México: Siglo XXI.

Casado, D. (1991). Panorámica de la discapacidad. Barcelona: Intress.

Choque, R. (2009). Ecosistema educativo y fracaso escolar. Revista Iberoamericana de Educación, 49, 1-9.

Croso, C. (2010). El derecho a la educación de personas con discapacidad. Revista Latinoamericana de Educación Inclusiva, 4(2), 79-95.

Cifuentes, M. (2008). La justicia a las identidades colectivas, más allá del dilema distribución-reconocimiento. Jurid, 5, 123138.

Cuervo, C., Pérez, L., \& Trujillo, A. (2008). Modelo conceptual colombiano de discapacidad e inclusión social. (Tesis de Maestría en Discapacidad e Inclusión Social). Universidad Nacional de Colombia, Bogotá, D. C., Colombia.

Damm, X. (2008). Representaciones y actitudes del profesorado frente a la integración de niños/as con necesidades educativas especiales al aula común. Revista Latinoamericana de Educación Inclusiva, 3(1), 25-35.

Dávila, P., Garmendia, L., \& Lauzurica, A. (2016). Las personas con discapacidad, el derecho a la educación y la Convención sobre los Derechos del Niño en América Latina. Revista Latinoamericana de Educación Inclusiva, 4(2), 97-117.

Foucault, M. (1972). Vigilar y castigar, nacimiento de la prisión. Buenos Aires: Siglo Veintiuno Editores.

Freire, P. (1995). Pedagogía del oprimido. México, D. F.: Siglo XXI.

Giménez, G. (2001). Cultura, territorio y migraciones. Aproximaciones teóricas. Recuperado de: $<$ http://www.redalyc.org/ articulo.oa?id=74702202> ISSN 01887017

Gómez, A. (2014). La inclusión social despojante, el multigrupo y la covisualidad. Conceptualizando a partir de las experiencias. En M. Rifà-Valls, L. Duarte-Campderrós, \& M. PonferradaArteaga (Eds.), Nuevos desafíos para la inclusión social y equidad en instituciones de educación superior (pp. 267-284). Barcelona: Miseal.

Hahn, H. (1988). The politics of physical differences: Disability and discrimination, Journal of Social Isssues, 44(1), 39-47.

Honneth, A. (1997). La lucha por el reconocimiento. Por una gramática de los conflictos sociales. Barcelona: Grijalbo.

Juárez, M., Comboni, S., \& Garnique, F. (2010). De la educación especial a la educación inclusiva. Argumentos, 23(62), 41-83. Recuperado de: http://www.scielo.org.mx/ 
scielo.php?script $=$ sci arttext\&pid $=\mathrm{S} 0187$ $57952010000100003 \& \operatorname{lng}=$ es\&tlng=es

Mignolo, W. (2010). Desobediencia epistémica: retórica de la modernidad, lógica de la colonialidad y gramática de la descolonialidad. Buenos Aires: Ediciones del Signo.

Nussbaum, M.(2008).Paisajes delpensamiento, la inteligencia de las emociones. Barcelona: Paidós Ibérica.

Palacios, A. (2008). El modelo social de discapacidad: orígenes, caracterización y plasmación en la convención internacional sobre los derechos de las personas con discapacidad. Madrid: Cinca.

Pava-Ripoll, N. A. (2017). Discapacidad y configuración del Capital Emocional (CE): el caso de tres padres. Revista Latinoamericana de Ciencias Sociales, Niñez y Juventud, 15(2), 951-963. doi:10. 11600/1692715x.1521022062016

Puig, R. (1990). Concepciones, paradigmas y evolución de las mentalidades sobre la discapacidad. En SIIS (Ed.), Discapacidad e información (pp. 63-96). Madrid: Real Patronato de Prevención y Atención a Personas con Minusvalía.

Quijano, A. (2000). Colonialidad del poder, eurocentrismo y América Latina. En E. Lander (Comp.), La colonialidad del saber: eurocentrismo y ciencias sociales. Perspectivas Latinoamericanas (pp. 201246). Buenos Aires: Clacso.

Real Academia Española (2001). Diccionario de la lengua española (22 ed.) Recuperado de: http://www.rae.es/rae.html.

Restrepo, E., \& Rojas, A. (2010). Inflexión decolonial. Fuentes, conceptos y cuestionamientos. Bogotá, D. C.: Instituto de Estudios Sociales y Culturales Pensar, Maestría en Estudios Culturales, Universidad Javeriana.

Skliar, C. (2011). Diez escenas educativas para narrar lo pedagógico. Planilla Educativa Universidad de Manizales, (8), 11-22.

Valdés. A., \& Monereo, C. (2012). Desafíos a la formación del docente inclusivo: la identidad profesional y su relación con los incidentes críticos. Revista
Latinoamericana de Educación Inclusiva, 6(2), 193-208.

Walker, J. (2013). Igualdad de derechos. Igualdad de oportunidades. La educación inclusiva para niños con discapacidad. Johannesburgo: Handicap International. 